\title{
Immature Synaptic Contacts in Human Congenital Hydrocephalus. An Electron Microscopic study
}

\author{
Orlando J Castejón* \\ Biological Research Institute "Drs. Orlando Castejón and Haydee Viloria de Castejón", Faculty of Medicine, Venezuela \\ *Corresponding author: Orlando J Castejón, Instituto de Investigaciones Biológicas “Drs. Orlando Castejón and Haydee Viloria de \\ Castejón", Facultad de Medicina, Venezuela
}

\section{ARTICLE INFO}

Received: 㓞 February 10, 2019

Published: 幽 February 26, 2019

Citation: Orlando J Castejón. Immature Synaptic Contacts in Human Congenital Hydrocephalus. An Electron Microscopic study. Biomed J Sci \& Tech Res 15(2)-2019. BJSTR. MS.ID.002670.

Keywords: Immature Synapses; Congenital Hydrocephalus; Arnold Chiari Malformation; Electron Microscopy

\begin{abstract}
Fourteen surgical biopsies of cortical brain parenchyma from patients with congenital hydrocephalus ranging from 12 days to 10 years old were examined with transmission electron microscopy to study immature axosomatic and axodendritic synaptic contacts. The hydrocephalic brain parenchyma was characterized as immature tissue due to the presence of microdendritic filopodia, distended extracellular spaces, and axonal and dendritic grow cones. The first group formed by earliest immature synapses were featured by close apposition of electron dense pre- and postsynaptic synaptic membrane complexes lacking synaptic cleft and pre- and postsynaptic densities. A second group displayed electron dense pre- and postsynaptic synaptic membrane complex, thin pre- and postsynaptic densities, synaptic cleft, and few synaptic vesicles. A third group consisting of immature axosomatic synapses exhibits only electron dense pre- and postsynaptic membranes and the synaptic cleft. The immature brain parenchyma showed isolated and vacant presynaptic endings, axonal and dendritic cones. These findings provide novel insights into synapse development in a pathological environment represented by the interstitial hydrocephalic edema.
\end{abstract}

\section{Introduction}

Aggelopoulos et al. [1] analyzed the synaptogenesis in the dorsal lateral geniculate nucleus of the rat and demonstrated that during the first stage, which spans the first 4 days of life, there are only a few immature synapses scattered throughout the nucleus. During the first two postnatal weeks, and particularly during the second stage, the presence of membrane specializations that resemble vacant postsynaptic endings, and in the third stage, which spans a period between days 10 and 20, beginning of myelination and by diminution of growth cones, degenerating profiles and vacant postsynaptic endings. In previous papers we have reported synaptic plasticity and synaptic degeneration in human congenital hydrocephalus [2-5]. In the present study fourteen neonate patients with age ranging from 1 day neonates to 10 years infant patients were examined to characterize the presence of immature synaptic contacts in the hydrocephalic swollen brain parenchyma. Such study is basically important to study human synaptogenesis and abnormal neural microcircuits in pathological conditions.

\section{Material and Methods}

Cortical biopsies of 14 infant patients, ranging from 12 days to 10 years old, with clinical diagnosis of congenital hydrocephalus and Arnold-Chiari malformation were taken from the frontal and parietal cortical regions, and examined with the transmission electron microscope. The (Table 1) contains the clinical data and lists the cortical regions from which the cortical biopsies were taken. This neurosurgical study was performed with authorized parent consent, and according to basic principles of Helsinki Declaration. Two to five mm thick cortical biopsies were immediately fixed in the surgical room in $4 \%$ glutaraldehyde- $0.1 \mathrm{M}$ phosphate or cacodylate

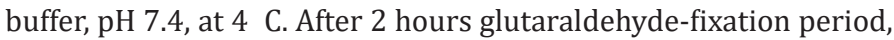
the cortical biopsies were washed in similar $0.1 \mathrm{M}$ phosphate or cacodylate buffer, $\mathrm{pH} 7.4$ to eliminate the remaining blood from the cortical biopsy and avoid oxidation of the primary fixative solution. The cortical biopsies were then divided into approximately $1 \mathrm{~mm}$ fragments and observed under a stereoscopic microscope to check the quality of sample fixation, the glutaraldehyde diffusion rate, and the brownish coloration of the surface and deeper cortical regions, indicative of good glutaraldehyde fixation by immersion technique.

Secondary fixation in $1 \%$ osmium tetroxide- $0.1 \mathrm{M}$ phosphate buffer, $\mathrm{pH} 7.4$, was carried out for 1-2 hours at 4 खC. Black staining of the cortical slices also was observed under a stereoscopic 
microscope to check osmium tetroxide diffusion rate and tissue black staining. They were then rinsed for 5 to 10 minutes in phosphate or cacodylate buffer of similar composition to that used in the fixative solution, dehydrated in increasing concentrations of ethanol, and embedded in Araldite or Epon. For proper orientation during the electron microscope study and observation of cortical layers, approximately 0.1 to $1 \nabla \mathrm{m}$ thick sections were stained with toluidine blue and examined with a Zeiss photomicroscope.

Table 1: Neurosurgical Study of Congenital Hydrocephalus.
Light microscopic studies of neurons, glial cells, and blood-brain barrier were performed. Ultrathin sections, obtained with PorterBlum and LKB ultramicrotomes, were stained with uranyl acetate and lead citrate, and observed in a JEOL 100B transmission electron microscope (TEM) at magnifications ranging from 20,000 to $90,000 \mathrm{X}$. For each cortical biopsy, approximately 50 electron micrographs were systematically studied. Digital images were Photoshop analyzed.

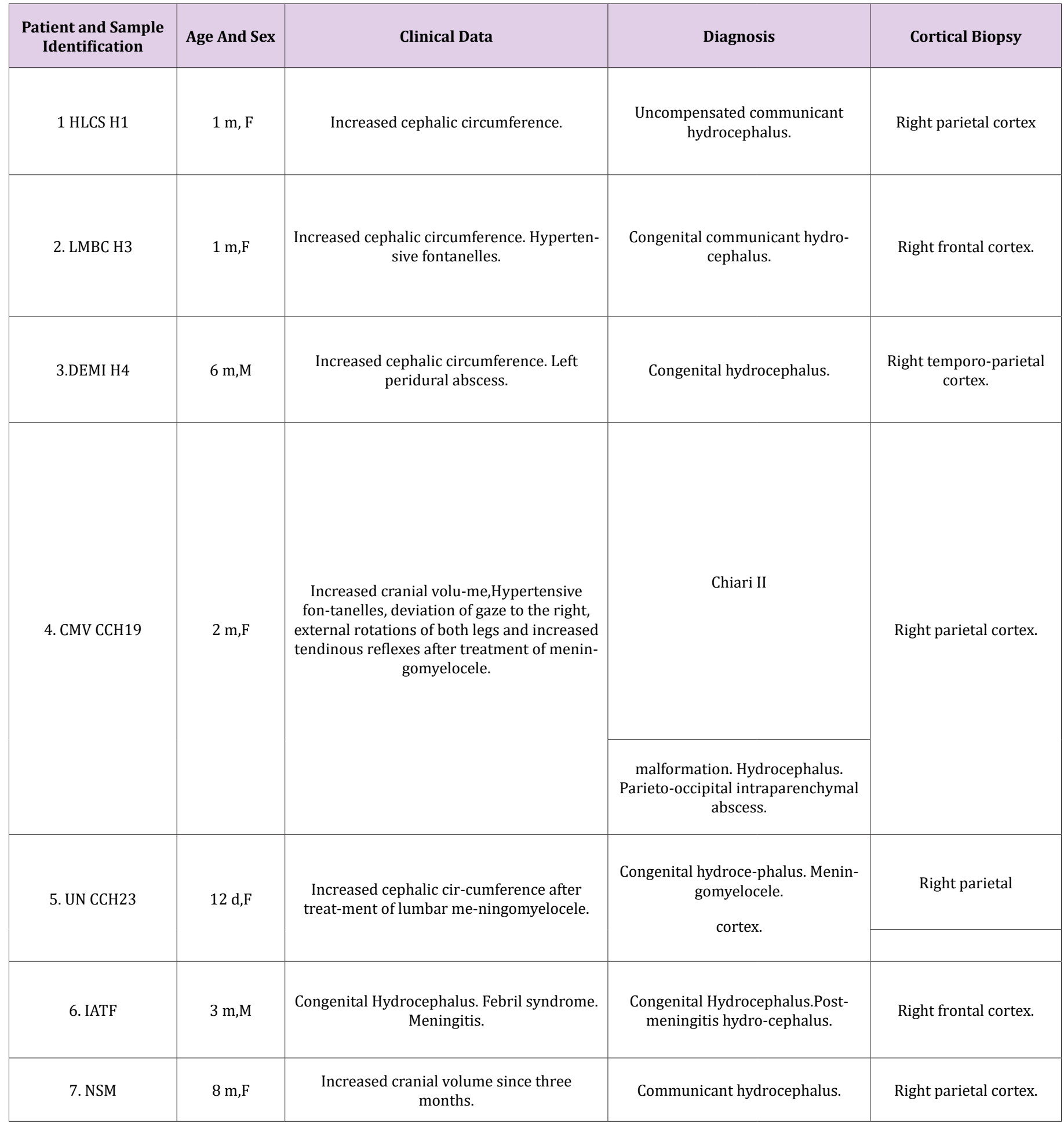




\begin{tabular}{|c|c|c|c|c|}
\hline 8. GAAPG CCH23 & $3 \mathrm{~m}, \mathrm{M}$ & $\begin{array}{l}\text { Meningeal syn- } \\
\text { drome. Tonic-clon- } \\
\text { ic convulsions, } \\
\text { increased cephalic } \\
\text { circumference. }\end{array}$ & $\begin{array}{l}\text { Congenital } \\
\text { hydroceph- } \\
\text { alus }\end{array}$ & Frontal cortex. \\
\hline 9. RGG CCH26 & $4 \mathrm{~m}, \mathrm{~F}$ & $\begin{array}{l}\text { Increased cephalic } \\
\text { circumference, } \\
\text { hyper-tensive } \\
\text { fontanelles. }\end{array}$ & $\begin{array}{c}\text { Congenital } \\
\text { hydroce-pha- } \\
\text { lus. }\end{array}$ & Right frontal cortex. \\
\hline 10.HR CCH45 & $2 y, F$ & $\begin{array}{l}\text { Increased cranial } \\
\text { volume since } 4 \\
\text { months of age. }\end{array}$ & $\begin{array}{l}\text { Communicant } \\
\text { congenital } \\
\text { hydro-ceph- } \\
\text { alus. }\end{array}$ & Right frontal cortex. \\
\hline 11.ISS CCH55 & $7 \mathrm{~m}, \mathrm{M}$ & $\begin{array}{l}\text { Increased cranial } \\
\text { volume. Diagnosis } \\
\text { of subarachnoid } \\
\text { hemorrhage after } \\
\text { axial computer } \\
\text { tomography. }\end{array}$ & $\begin{array}{l}\text { Communicant } \\
\text { congenital } \\
\text { hydro-ceph- } \\
\text { alus. }\end{array}$ & Right frontal cortex. \\
\hline 12. СC H9 & $10 \mathrm{y}, \mathrm{M}$ & $\begin{array}{l}\text { Increased cranial } \\
\text { volume. }\end{array}$ & $\begin{array}{l}\text { Communicant } \\
\text { hydroceph- } \\
\text { alus. }\end{array}$ & Parietal cortex. \\
\hline \multirow{2}{*}{ 13. EV H10 } & $5 y, F$ & Increased cephalic & \multirow{2}{*}{$\begin{array}{l}\text { Communicant } \\
\text { hydroceph- } \\
\text { alus. }\end{array}$} & \multirow{2}{*}{ Parietal cortex. } \\
\hline & circumference. & & & \\
\hline 14.CMV CCH19 & $2 \mathrm{~m}, \mathrm{~F}$ & $\begin{array}{l}\text { Increased cranial } \\
\text { volume, hyperten- } \\
\text { sive fontanelles, } \\
\text { deviation of gaze to } \\
\text { the right, external } \\
\text { rotation of both } \\
\text { legs. }\end{array}$ & $\begin{array}{l}\text { Chiari II mal- } \\
\text { formation. } \\
\text { Hydrocepha- } \\
\text { lus. Parie- } \\
\text { to-occipital } \\
\text { intraparen- } \\
\text { chymal } \\
\text { abscess. }\end{array}$ & Right parietal cortex. \\
\hline
\end{tabular}

\section{Results}

Close examination of hydrocephalic brain parenchyma from patients ranging from two to seven postnatal months old show incomplete tissue maturation as revealed by the presence of dendritic filopodia, presence of extracelular space, immature synaptic contacts, and axonal and dendritic grow cones the axodendritic contacts appeared formed by extremely swollen preand postsynaptic endings due to the hydrocephalic edema (Figure 1). The first group formed by earliest immature synapses were featured by close apposition of electron dense pre- and postsynaptic synaptic membrane complexes lacking synaptic vesicles, synaptic cleft and pre- and postsynaptic densities. These kinds of synapses could be categorized as silent synapses (Figure 2). A second group displayed electron dense pre- and postsynaptic synaptic membrane complex, thin pre- and postsynaptic densities, synaptic cleft, and few docked synaptic vesicles anchored to the presynaptic membranes, and microtubules in the neck of postsynaptic dendrites, swollen degenerated pre- and postsynaptic endings also are found (Figure 3). These group of synapses are therefore considered as exerting active chemical neurotransmission. Most of synapses visualized in this second group correspond to the axodendritic asymmetrical and symmetrical types. 


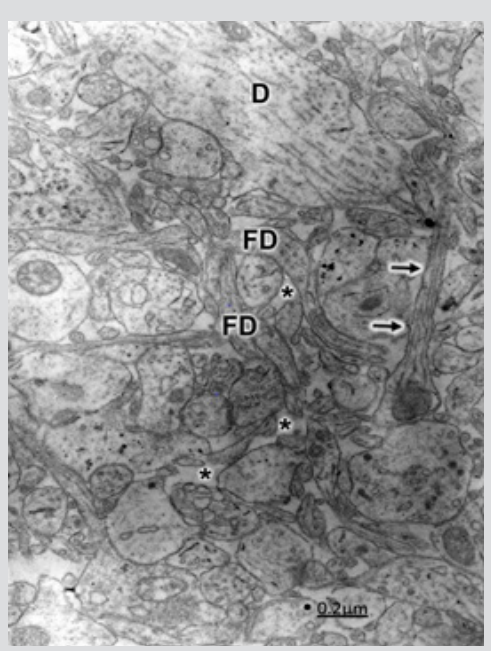

Figure 1: Arnold-Chiari malformation. Hydrocephalus. Right parietal cortex. Immature neuropil showing a dendritic spine with a long neck and a mushroom shaped body (short arrows). The neck exhibits microtubules. A dendritic shaft (D) and filopodics dendrites (FD) also are distinguished. Note the dilated and electron lucid extracellular space (asterisks) that features the immature edematous hydrocephalic neuropil, occupied by the non-circulating and electron lucid cerebrospinal fluid.

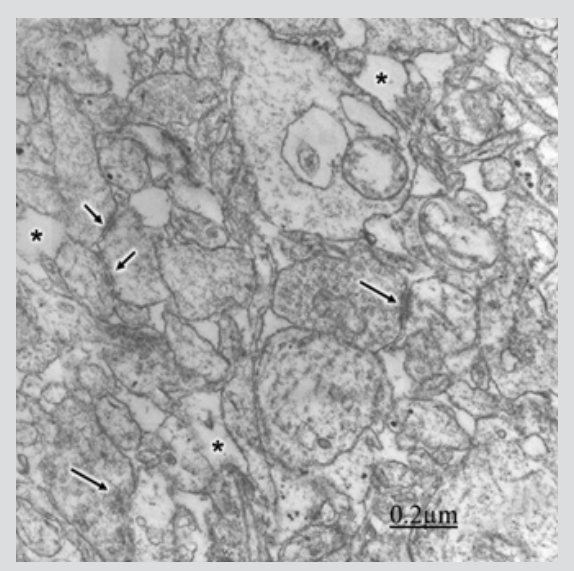

Figure 2: Congenital hydrocephalus. Right frontal cortex. Immature axodendritic contacts (short arrows) showing electron dense synaptic membrane apposition and absence of presynaptic vesicles (short arrows). The long arrow at the center of image points out dense pre- and postsynaptic membranes separated by the synaptic cleft. Note the absence of synaptic vesicles. The asterisks label the enlarged extracellular space. The long arrow at the left lower corner of the figure indicates a degenerated immature synapse.

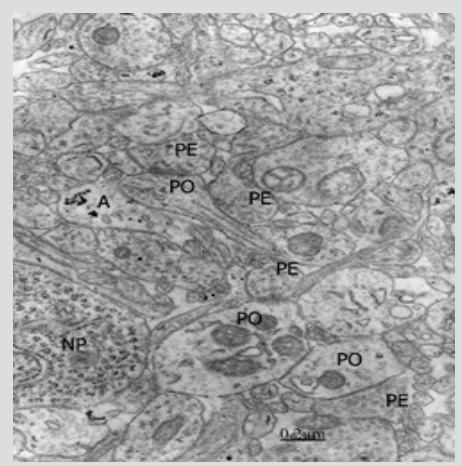

Figure 3: Congenital hydrocephalus. Right frontal cortex. Immature and swollen axodendritic pre- and postsynaptic endings (PE, PO) synaptic contacts featured by few synaptic vesicles in the presynaptic ending (PE), electron dense pre- and postsynaptic membranes separated by a narrow synaptic cleft, and pre- and postsynaptic densities resembling symmetrical synapses. The neck and body of postsynaptic dendrite and the postsynaptic ending (PO) exhibit microtubusles. Perisynaptic astrocyte cytoplasm (A) containing glycogen granules also is observed. Another neighbouring swollen axodendritic contacts also are seen. 
A third group was represented by axosomatic synapses on nonpyramidal neurons showing electron dense pre- and postsynaptic membranes, synaptic cleft, few dispersed clear synaptic vesicles, presence of dense cored vesicles, and absence of pre-and postsynaptic densities (Figure 4). In addition, we found isolated and swollen presynaptic endings without postsynaptic knobs and containing synaptic vesicles, presumably corresponding to vacant and degenerated presynaptic endings or an axonal grow cone (Figure 5).

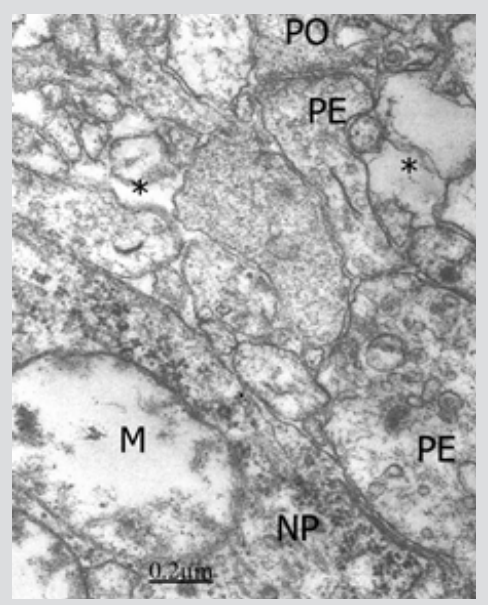

Figure 4: Congenital hydrocephalus. Right parietal cortex. Immature presynaptic ending (PE) making axosomatic synaptic contact on a swollen non-pyramidal neuron (NP) and showing dispersed clear synaptic vesicles and dense-cored vesicles, and absence of pre- and postsynaptic densities, and exhibiting synaptic cleft and absence of pre and postsynaptic densities. Another immature pre- and post-synaptic endings ( $\mathrm{PE}, \mathrm{sPO})$ establish an axodendritic contact without presynaptic vesicles and lacking synaptic cleft. sThe postsynaptic neuron exhibits swollen mitochondria (M).1. Note the dilated extracellular space (asterisk).

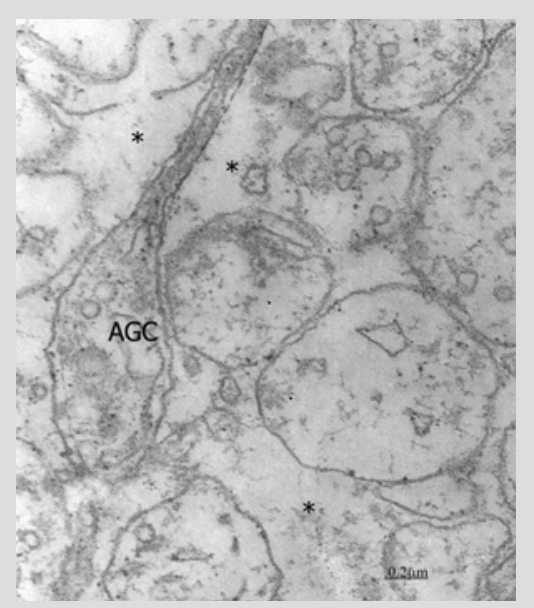

Figure 5: Arnold-Chiari malformation. Congenital Hydrocephalus. Right parietal cortex. Severe hydrocephalic edema. The axonal grow cone (AGC)) shows a long presynaptic neck and an oval terminal ending with few and enlarged synaptic vesicles. Very edematous and undifferentiated nerve processes are observed in the close neuropsil separated by dilated extracellular space (asterisks).

\section{Discussion}

In the present study we have demonstrated different stages of synaptogenesis in a brain parenchyma with interstitial hydrocephalic edema. Formation of synapses is one of the most important step in neuronal differentiation and the establishment of neuronal circuits [6]. Some immature synapses, as illustrated in figure two, contain a few clear vesicles but lack typical synaptic membrane specializations, suggesting that they are physiologically immature, as suggested by Vaca et al. [ 7]. In addition, the presence of microphilopodia in our study indicate that there is incomplete tissue maturation.

The edematous interstitial hydrocephalic edema induces abnormal synaptogenesis. Synapse formation is a complex, incompletely understood process that has received only limited investigation in man despite the importance of synaptic dysfunction in common disorders such as epilepsy and mental retardation [8]. According to Bogolepov et al. [9], the initial stage in the synapses formation is the desmosome-like junction. The second stage is 
appearance of synaptic vesicles in the area of this contact. The third stage includes development of pre- and postsynaptic membranous specialization, and owing to this the contact acquires either asymmetric or symmetric appearance. Li et al. [10] by means of in vivo time-lapse imaging and serial section electron microscopy demonstrated developmental synaptic rearrangements, and dynamic dendrites having a high density of immature synapses, whereas stable dendrites have sparser, mature synapses. In the hydrocephalic brain parenchyma we observed synaptic plasticity and degeneration $[4,5]$.

Perisynaptic astrocytes containing glycogen granules were observed surrounding the synaptic contacts for producing energy for synaptic maturation.

In the present study we have visualized microtubules in both pre- and postsynaptic endings. According to Bodaleo et al. [11], microtubule-associated protein 1B (MAP1B) is expressed predominantly during the early stages of development of the nervous system, where it regulates processes such as axonal guidance and elongation. Biochemical and physiological correlates of immature synapses.

Maggy et al. [12] have reported in the hippocampus at birth that most glutamatergic synapses are immature and functionally "silent" either because the neurotransmitter is released in insufficient amount to activate low-affinity alpha-amino-3-hydroxy-5-methyl4-isoxazole propionate receptors or because the appropriate receptor system is missing or nonfunctional. In the newborn rat a brief application of nicotine at immature Schaffer collateralCA1 connection strongly enhances neurotransmitter release and converts presynaptically silent synapses into conductive ones.

According to Vaca [7], functional cholinergic transmission occurs within minutes of contact between the growth cone and a receptive target. These early contacts contain a few clear vesicles but lack typical ultrastructural specializations and are physiologically immature.

Since differentiation depends on many antecedent developmental events, synaptogenesis can be affected by several factors: errors in neuronal proliferation, migration, and differentiation. The challenge to the neurobiologist is to detect and evaluate the minor alterations in neuronal differentiation that could account for the structural basis of the clinical manifestations, Further exploration of synaptogenesis, particularly the influence of gene products and epigenetic factors on synapse maturation, will increase our understanding of the pathogenesis of conditions in which "morphology" seems normal but function is abnormal [8].

Miyazawa $\mathrm{T}$ and Sato $[13,14]$ studying hippocampal synaptogenesis in hydrocephalic HTX-rats using a monoclonal antisynaptic vesicle protein antibody considered that hippocampal synaptogenesis is more resilient than that of the cerebral cortex in hydrocephalic brains. Miyazawa et al. [15] considered that despite the presence of continuous pressure due to progressive ventricular dilatation after birth, synaptogenesis in the hydrocephalic cerebral cortex may be relatively resilient.

Balasubramaniam and Del Bigio [16] found at transcriptional level that young rats with kaolin-induced subacute hydrocephalus showed overexpression of genes involved in synaptic transmission in parallel to genes associated with protective and compensatory mechanisms. According to these Authors, these results indicate that there is an age- and duration-dependent difference in the gene expression profiles of kaolin-induced hydrocephalus, and open present avenues for future research.

During early neocortical development synaptic vesicle pools are not yet fully differentiated and their replenishment may be slow, thus resulting in EPSP amplitude depression. The decrease in the probability of neurotransmitter release may be the result of an altered $\mathrm{Ca}(2+)$ control in the presynaptic terminal with a reduced $\mathrm{Ca}(2+)$ influx and/or a higher $\mathrm{Ca}(2+)$ buffering capacity. This may lead to a lower synaptic reliability and a weaker short-term synaptic depression with maturation [17].

$\mathrm{N}$-cadherin, a membrane of the $\mathrm{Ca} 2+$-dependent cell adhesion molecule family, play essential and specific roles in morphogenesis and histogenesis, as well as in the transduction of long-range growth and differentiation signals of nerve and muscle cells [18]. $\mathrm{N}$-cadherin at the level of synaptic contacts may play a critical role in maintaining nascent pre- and postsynaptic membranes in apposition, enabling incipient synapses to acquire function and contribute to long-term potentiation [19]. N-cadherin would mediate the formation of cell-cell synaptic junctions by homophilic interactions through their extracellular domains [20].

CaMKII alpha also is localized in the brain cortex and in the three-layered structure of developing cerebellar cortex contributing to stabilization of neurons and synapses during development [21].

The disc-large (DLG)-membrane-associated guanylate kinase (MAGUK) family of proteins forms a central signaling hub of the glutamate receptor complex. Among this family, some proteins regulate developmental maturation of glutamatergic synapses, a process vulnerable to aberrations, which may lead to neurodevelopmental disorders. By controlling the pace of silent synapse maturation, the opposing but properly balanced actions of PSD-93 and PSD-95 are essential for fine-tuning cortical networks for receptive field integration during developmental critical periods, and imply aberrations in either direction of this process as potential causes for neurodevelopmental disorders [22].

Silent synapses show NMDA receptor (NMDAR)-mediated synaptic responses, but not AMPAR-mediated synaptic responses. A prevailing hypothesis states that silent synapses contain NMDARs, but not AMPARs. However, alternative presynaptic hypotheses, according to which AMPARs are present at silent synapses, have been proposed; silent synapses show slow glutamate release via a 
fusion pore, and glutamate spillover from the neighboring synaptic terminals [23].

\section{Acknowledgement}

This paper has been partially carried out through a subvention from Castejón Foundation and the logistic support of Biological Research Institute. Faculty of Medicine. Zulia University and CONDES-LUZ.

\section{References}

1. Aggelopoulos N, Parnavelas JG, Edmunds S (1989) Synaptogenesis in the dorsal lateral geniculate nucleus of the rat. Anat Embryol (Berl) 180(3):243-257

2. Castejón OJ (1994) Transmission electron microscope study of human hydrocephalic cerebral cortex. J Submicrosc Cytol Pathol 26(1): 29-39.

3. Castejón OJ, Valero C, Díaz M (1995) Electron microscopy of cerebral cortex in Arnold-Chiari Type II Malformation. Report of two Cases. J Submicrosc Cytol Pathol 27: 401-405.

4. Castejón OJ (2006) Synaptic plasticity and synaptic degeneration in human congenital hydrocephalus. J Pedriat Neurol 6: 99-107.

5. Castejón OJ (2010) Submicroscopic pathology of human and experimental hydrocephalic cerebral cortex. Folia Neuropathol 48(3): 159-174.

6. Zecevic N (1998) Synaptogenesis in layer I of the human cerebral cortex in the first half of gestation. Cereb Cortex 8(3): 245-252.

7. Vaca K (1988) The development of cholinergic neurons. Brain Res 472(3): 261-286

8. Becker LE (1991) Synaptic dysgenesis. Can J Neurol Sci 18(2): 170-180.

9. Bogolepov NN, Frumkina LE, Iakovleva NI, Koroleva SK (1987) Possible mechanisms of synapse formation during ontogenesis. Arkh Anat Gistol Embriol 92(5): 20-27.

10. Li J, Erisir A, Cline H (2011) In vivo time-lapse imaging and serial section electron microscopy reveal developmental synaptic rearrangements. Neuron 69(2): 273-286.

11. Bodaleo FJ, Montenegro-Venegas C, Henríquez DR, Court FA, Gonzalez-Billault C, et al. (2016) Microtubule-associated protein 1B (MAP1B)-deficient neurons show structural presynaptic deficiencies in vitro and altered presynaptic physiology. Sci Rep 6: 30069.

\section{ISSN: 2574-1241}

DOI: 10.26717/BJSTR.2019.15.002670

Orlando J Castejón. Biomed J Sci \& Tech Res

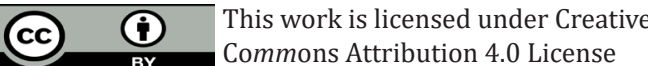

Submission Link: https://biomedres.us/submit-manuscript.php
12. Maggi L, Le Magueresse C, Changeux JP, Cherubini E (2003) Nicotine activates immature "silent" connections in the developing hippocampus. Proc Natl Acad Sci USA 100(4): 2059-2064.

13. Miyazawa T, Sato K (1991) Hippocampal synaptogenesis in hydrocephalic HTX-rats using a monoclonal anti-synaptic vesicle protein antibody. Childs Nerv Syst 7(3):121-128.

14. Miyazawa T, Sato K (1994) Hippocampal synaptogenesis in hydrocephalic HTX-rats using a monoclonal anti-synaptic vesicle protein antibody. Brain Dev 16(6):432-436

15. Miyazawa T, Nishiye H, Sato K, Kobayashi R, Hattori S, et al. (1992) Cortical synaptogenesis in congenitally hydrocephalic HTX-rats using monoclonal anti-synaptic vesicle protein antibody. Brain Dev 14(2): 75-79.

16. Balasubramaniam J, Del Bigio MR (2002) Analysis of age-dependent alteration in the brain gene expression profile following induction of hydrocephalus in rats. Exp Neurol 173: 105

17. Feldmeyer D, Radnikow G (2009) Developmental alterations in the functional properties of excitatory neocortical synapses. J Physiol 587(Pt 9):1889-1896.

18. Castejón OJ (2017) N-Cadherin immunohistochemistry in p14 developing rat cerebellar cortex. J Adv Microsc Res (USA) 12: 34-39.

19. Bozdagi O, Shan W, Tanaka H, Benson DL, Huntley GW (2000) Increasing numbers of synaptic puncta during late-phase LTP: N-cadherin is synthesized, recruited to synaptic sites, and required for potentiation. Neuron 28: 245-259.

20. Katz BZ, Levenberg S, Yamada KM, Geiger B (1998) Modulation of cellcell adherens junctions by surface clustering of the N-cadherin cytoplasmic tail. Exp Cell Res 243: 415-424.

21. Castejón OJ (2017) Immunohistochemistry of $\mathrm{Ca}^{2+} /$ Calmodulin-dependent protein kinase ii alpha in p14 developing rat cerebellar cortex using confocal laser scanning microscopy. J Adv Microsc Res (USA) 12: 11-16.

22. Favaro PD, Huang X, Hosang L, Stodieck S, Cui L, et al. (2018) An opposing function of paralogs in balancing developmental synapse maturation. PLoS Biol 16(12): e2006838.

23. Yoon JY, Choi S (2017) Evidence for presynaptically silent synapses in the immature hippocampus. Biochem Biophys Res Commun 482(4): 1375-1380.

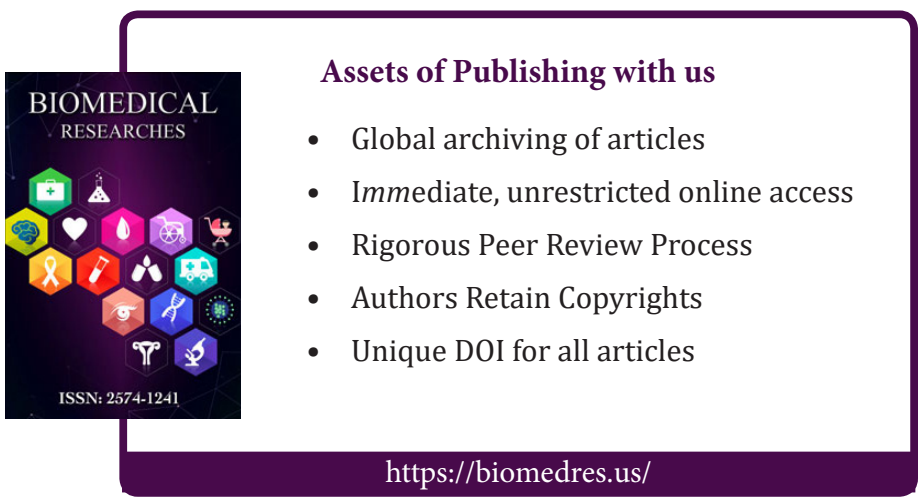


